\title{
Xylitol inhibits J774A.1 macrophage adhesion in vitro
}

\author{
Aline Siqueira Ferreira ${ }^{1 *}$, Maria Aparecida de Souza ${ }^{2}$, Nádia Rezende Barbosa Raposo ${ }^{1,3}$ \\ Ana Paula Ferreira ${ }^{2}$ and Silvio Silvério da Silva ${ }^{4}$ \\ ${ }^{I}$ Departamento de Alimentos e Toxicologia; Faculdade de Farmácia e Bioquímica; Universidade Federal de Juiz de \\ Fora; Juiz de Fora - MG - Brasil. ${ }^{2}$ Departamento de Parasitologia, Microbiologia e Imunologia, Instituto de \\ Ciências Biológicas; Universidade Federal de Juiz de Fora; Juiz de Fora - MG - Brasil. ${ }^{3}$ Instituto de Psiquiatria; \\ Faculdade de Medicina; Universidade de São Paulo; São Paulo - SP - Brasil. ${ }^{4}$ Departamento de Biotecnologia; \\ Escola de Engenharia de Lorena; Universidade de São Paulo; São Paulo - SP - Brasil
}

\begin{abstract}
The aim of this work was to evaluate the effect of xylitol on J774A.1 macrophage adhesion. Adhesion consisted of a three-hour interval, at room temperature, followed by washing and cell incubation at $37^{\circ} \mathrm{C} / 5 \% \mathrm{CO}_{2} / 48 \mathrm{~h}$. Xylitol was used to treat the cells either before (for 24h) or after the cell incubation (for 48h) at 5\% as final concentration in both the situations. It was found that xylitol was effective in preventing the adhesion in both the conditions in spite of the former being 100-fold greater and significant $(p<0.001)$. The results pointed to an important xylitol action on macrophage adhesion, which should be further investigated as an inflammatory control.
\end{abstract}

Key words: adhesion, J774A.1 macrophages; xylitol

\section{INTRODUCTION}

Macrophages are essential cellular components of the body's host defense system, having critical functions in both native and acquired immunity. The detection of pathogens is first carried out by these sentinel cells of the innate immune system located in the tissues that are in contact with the host's natural environment. As participants in innate immunity, macrophages protect the host during the early phase of an infection (Tiwari et al., 2008). Hence, it is believed that these cells can be involved in steady-state tissue homeostasis via the clearance of apoptotic cells and the production of growth factors. In the macrophages surface, there is a broad range of pathogen-recognition receptors that make them efficient in phagocytosis and induce the production of inflammatory cytokines (reviewed in Geissmann et al., 2010).

Macrophages have presentation antigen functions with antigen uptake and processing capabilities, expression of MHC class II and co-stimulatory molecules. Upon encounter with an antigen, these can release a variety of reactive oxygen species (superoxide anions, hydrogen peroxide and nitric oxide) as well as pro-inflammatory cytokines such as tumor necrosis factor alpha (TNF- $\alpha)$, interleukin-1 (IL-1) and interleukin-6 (IL-6) (reviewed by Mosser, 2003). Macrophages are adherent cells, seem to be obligatory for $\mathrm{T}$ cell activation induced by the concanavalin $\mathrm{A}$ (a mannose-binding lectin) and for B cell activation induced by the dextran-sulphate (Persson et al., 1978). Furthermore, macrophages need to adhere

*Author for correspondence: alinefarm@gmail.com 
to tissue surface to play their role. It could be a desired situation, e.g., in wound healing and remodeling of tissue. However, if an inflammatory process, like atherogenesis, occurs, macrophage adhesion to a tissue leads to a deleterious action (Lasser, 1983).

Xylitol is a non-immunogenic and safe carbohydrate (Zopf and Roth, 1996). There are few works reporting its action on the immune system. Takahashi et al. (2005) found that dietary xylitol was a more useful carbohydrate source than glucose to alleviate the growth during the immunological stress. This occurred because the metabolic energy used in the test diets (glucose or xylitol, $150 \mathrm{~g} / \mathrm{kg}$ ) was $13.1 \mathrm{MJ} / \mathrm{kg}$ and the effect of xylitol on the growth was not caused by an increase in the dietary energy density. Han et al. (2005) demonstrated that xylitol was capable of inhibiting Porphyromonas gingivalis lipopolysaccharide (LPS)-induced gene expression and protein synthesis of TNF- $\alpha$ and IL- 1 beta in the immunological cells. Xylitol also inhibited the LPS-induced nuclear factor kappa B activation in RAW 264.7 cells.

Another useful ability attributed to this compound (Sajjan et al., 2004, Masako et al., 2005, Ferreira et al., 2008), investigated in the present work also, concerns xylitol inhibition of cell adhesion to a surface, which is an effective and safe form of infection control (Zopf and Roth, 1996).This study is a first phase of an investigation about xylitol influence on J774A.1 macrophage adhesion with promising and innovative results, and considering the importance of this cell adhesion on the first steps of inflammation processes (Foxwell et al., 2001; Hidemura et al., 2003, Kadl and Leitinger, 2005).

\section{MATERIAL AND METHODS}

Macrophages from the J774A.1 cell line (purchased from American Type Culture Collection, Rockville, MD, USA) were cultured in the complete RPMI-1640 medium (Gibco BRL, Scotland, UK), supplemented with $10 \%$ heatinactivated FBS, $2 \mathrm{mM}$ L-glutamine, and 100 U. $\mathrm{mL}^{-1}$ penicillin and $100 \mu \mathrm{g} \cdot \mathrm{mL}^{-1}$ streptomycin in a humidified chamber (Thermo Fisher Scientific Inc., Ohio, USA) at $37{ }^{\circ} \mathrm{C}$ and $5 \% \quad \mathrm{CO}_{2}$ atmosphere. Initial macrophage concentration was $10^{6}$ cells. $\mathrm{mL}^{-1}$ of medium.
The cell viability under different conditions was determined by a modified Mosmann assay that employed mitochondrial-dependent reduction of MTT to formazan as previously described (Mosmann, 1983). The cells were incubated with $5 \%$ xylitol for $48 \mathrm{~h}$. Afterwards, they were pulsed with $10 \mu \mathrm{L}$ of MTT reagent $\left(5 \mathrm{mg} . \mathrm{mL}^{-1}\right)$ for $3 \mathrm{~h}$ at $37^{\circ} \mathrm{C}$, followed by 10 minutes incubation with 100 $\mu \mathrm{L}$ of stop-solution (isopropanol and sodium duodecil sulfate, 1: 2, v/v). After this period, absolute optical densities were read at $570 \mathrm{~nm}$ in a microplate reader (Molecular Devices, USA). As a control, the cells were treated with $10 \%$ formaldehyde during 10 minutes. Cells only in RPMI medium was cultivated and used as the control of $100 \%$ viability. This assay was carried out in triplicate.

The influence of xylitol (Fluka BioChemika, Switzerland) on the macrophage adhesion was evaluated in two different conditions. In the first one, a standardized number of cells was treated for $24 \mathrm{~h}$ prior to adhesion and in the other, xylitol was used to treat the cells for $48 \mathrm{~h}$ after the adhesion. In both cases, xylitol was used at $5.0 \%$ as final concentration. The adhesion consisted of a threehour period at room temperature in 24-well culture plates containing a cover slip. Non-adherent cells were removed by washing in RPMI medium and a new medium was substituted. Culture supernatants were harvested after $48 \mathrm{~h}$ incubation and macrophages were washed with $1.0 \mathrm{~mL}$ PBS $\mathrm{pH}$ 7.2, fixed with cold methanol and stained with Giemsa for absolute counting (optical microscopy, $1000 \mathrm{X}$ magnification). Two independent assays were carried out in duplicate. TNF- $\alpha$, IL-1, IL-10, IL-12(p40) in the culture supernatants were measured, individually, by two-site sandwich ELISA (BD Biosciences, CA, USA). The standard curve was obtained with recombinant mouse cytokine. The minimal detectable concentration in the test was $31.2 \mathrm{ng} / \mathrm{mL}$ for IL-10 and $15.6 \mathrm{ng} / \mathrm{mL}$ for TNF- $\alpha$, IL-1 and IL-12(p40). The reaction was developed with peroxidase-conjugated streptavidin, followed by the substrate mixture containing tetramethylbenzidine (TMB) as chromogen. Absorbances were determined at 450 $\mathrm{nm}$ in an ELISA plate reader (Molecular Devices, USA). Nitric oxide (NO) was determined using the method developed by Green et al. (1982).

Kruskal-Wallis test was performed to detect the significant difference between the control and the effect of xylitol used to treat the cells before and 
after the adhesion, followed by Dunn's multiple comparison test. Differences in inflammatory mediators between the groups were evaluated using the same test. Differences were considered to be significant when $p<0.05$.

\section{RESULTS}

Although 5\% xylitol did not interfere with the J774A.1 cells viability when compared to the control (cells on RPMI) $(p=0.675)$, it influenced the cell adhesion under both the assayed conditions. The non-parametric test could not detect a difference between the control group (median $=6750, \mathrm{Q}_{3}-\mathrm{Q}_{1}=5899$ ) and the experimental one $\left(\right.$ median $\left.=622, \mathrm{Q}_{3}-\mathrm{Q}_{1}=549\right)$ when xylitol was used after the adhesion. However, it was observed that on the control cover slips, the number of adhered cells was ten times higher. The difference can be clearly visualized in Figure 1.

Microphotographies, obtained in a representative situation of each experimental condition showed that xylitol was effective when used to treat the cells before the adhesion (Fig. 2B) and after (Fig. 2A) when compared to the control (Fig. 2C). However, in the latter situation, a greater action was achieved. Xylitol was still effective in inhibiting the cell surface adhesion when used after the adhesion.

Interleukins and NO levels were presented in Table 1.

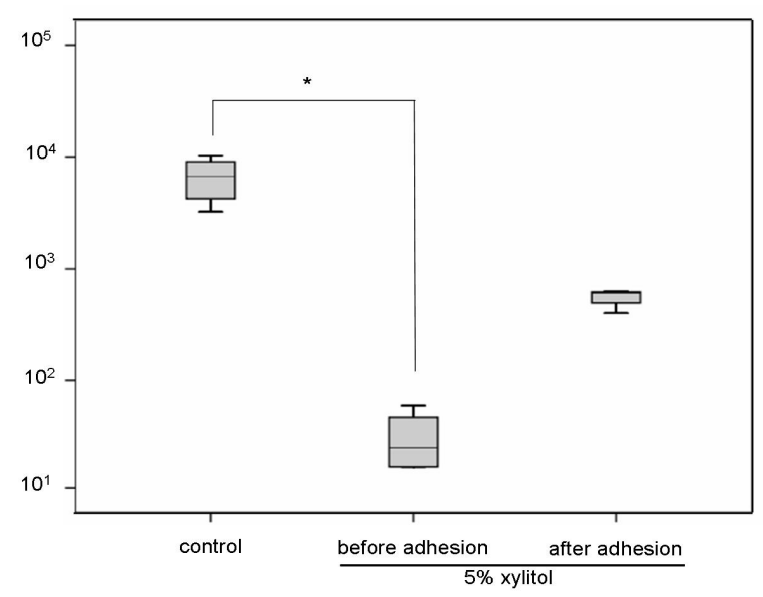

Figure 1 - Effect of 5\% xylitol on macrophage J774A.1 adhesion in vitro. Xylitol was effective on inhibiting cell adhesion both when used to treat cells before and after adhesion. Each point represents the median and the bars, interquartile range. Kruskal Wallis followed by Dunn's test was performed $(* \mathrm{p}<0.001)$. Data are representative of two independent assays carried out in duplicate.
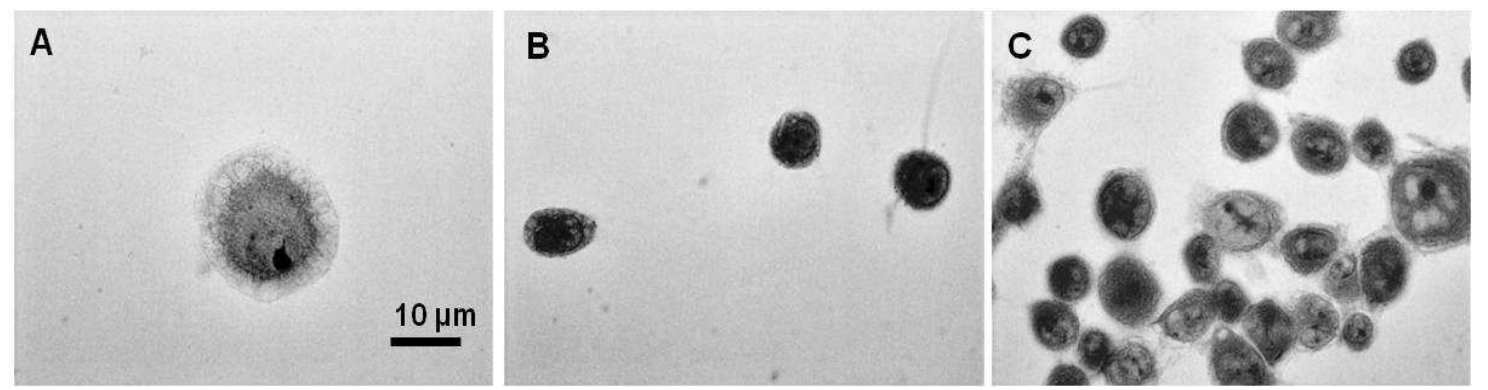

Figure 2 - Effect of 5\% xylitol on macrophage J774A.1 adhesion in vitro. Period of adhesion consisted of one three-hour interval, at room temperature, followed by washing and medium replacement, and cell incubation for 48 hours, $37^{\circ} \mathrm{C}, \mathrm{CO}_{2} 5 \%$. A) Xylitol used to treat cells for 24 hours before adhesion; B) Xylitol added in the medium after adhesion and C) Control, without xylitol. Microphotographies were representative for each tested condition. Bar scale: $10 \mu \mathrm{m}$. 
Table 1 - Inflammation modulators levels in culture supernatant, TNF- $\alpha$, IL-12, IL-10 and IL-1 in pg. mL ${ }^{-1}$ and NO in $\mu \mathrm{M}$. Measures were performed in triplicate using samples obtained in two different assays $(\mathrm{n}=6)$. Results were expressed as mean \pm standard deviation.

\begin{tabular}{lccccc}
\hline & NO & TNF- $\alpha$ & IL-12 & IL-10 & IL-1 \\
\hline Control & $62 \pm 2^{\mathrm{a}}$ & $21 \pm 1^{\mathrm{c}}$ & $18 \pm 3$ & ND & ND \\
XOH before & $7 \pm 2^{\mathrm{b}}$ & $9 \pm 1^{\mathrm{d}}$ & ND & ND & ND \\
XOH after & $12 \pm 2^{\mathrm{b}}$ & $9 \pm 2^{\mathrm{d}}$ & ND & ND & ND \\
\hline
\end{tabular}

ND: not detected. XOH: xylitol. Xylitol (at $5 \%$ ) was added before or after adhesion. ${ }^{\mathrm{a}, \mathrm{b}}$ NO was different between control group and the both treated with xylitol $(\mathrm{p}<0.001)$; ${ }^{\mathrm{c}, \mathrm{d}}$ TNF- $\alpha$ was different between control group and the both treated with xylitol (p < 0.001). Test used: Kruskal Wallis followed by Dunn's multiple comparison test.

\section{DISCUSSION}

Xylitol is a GRAS compound widely used in oral products due to its non- and anti-cariogenic properties (Pepper and Olinger, 1988; 'Lon' Jones, 2003). The variety of xylitol applications, such as candies, chewing gums, tooth paste (Steibnerg et al., 1992, Kontiokari et al., 1998; Vernacchio et al., 2007) highlights its potential as a component of such products. Here, as expected (Ferreira et al., 2008), xylitol did not influence the viability of the cultures tested. Other authors (Naaber et al., 1996; Zabner et al., 2000; 'Lon' Jones, 2003; Sajjan et al., 2004; Masako et al., 2005) have found similar results. The un-detected levels of IL-1, IL-10 and IL-12 could be explained due to the lower concentration of macrophages. Since they had not been adhered to the cover slips, they were discarded when the plate was washed. In the control, 4000 cells were estimated in $1.0 \mathrm{~mL}$ of RPMI medium, which was really diluted in the supernatant. If xylitol was added before the adhesion, the number of cells was very small $(<40$ cells/ well). Hence, it was not possible to conclude if the lower NO and TNF- $\alpha$ levels was due to xylitol or also because of the lower number of macrophages in these situation. These determinations should also be done with a phlogiston agent, such as LPS, added in the culture medium.

The ability of exogenous sugars to block these specific receptors and/or to competitively displace bacteria from their attachment sites on the cells may provide an adjunctive anti-inflammatory and/or antimicrobial treatment (Lloyd et al., 2007). Xylitol used to treat the cells after the infection acted in a non-specific, but satisfactory manner to inhibit the cell adhesion to a surface. Surprisingly, when macrophages were previously treated with 5\% xylitol, less than 40 cells adhered per cover slip. This was a preliminary study and only $5 \%$ xylitol was tested, since it was the concentration most studied in the literature.

Carbohydrates play a key role in cell adhesion. Complex carbohydrates coat the surfaces of the cells and have the potential to carry the information necessary for the cell-cell recognition. The pretreatment of the isolated lymphocytes with mannose-6-phosphate, or mannose phosphate polysaccharide resulted in binding inhibition. More specifically, mammalian alveolar macrophages adhered to polyacrilamide surfaces derivatized with mannose residues. Adhesion was blocked by the soluble D-mannose, suggesting that a reported cell-surface carbohydrate receptor on macrophages can mediate the cell adhesion (Brandley and Schnaar, 1986).

In the literature, few works describe the effect of carbohydrates (different to xylitol) on the macrophage adhesion. In a recent study (Chen et al., 2010) a possible explanation for macrophage adhesion was addressed. Polysaccharide-rich fractions of Angelica sinensis used to treat the peritoneal macrophages improved the immunoreactivity through an increase in the intracellular adhesion molecule-1 (ICAM-1) and Toll-like receptor 4 (TLR 4) gene expressions. ICAM-1 importance for the cell adhesion and inflammation was previously reported (Perreti et al., 1996) and it was demonstrated that dexamethasone attenuated the inflammation acting on ICAM-1 expression.

This was the first study showing the action of the xylitol on an immunological cell adhesion. The adherence is a crucial step in inflammation. Xylitol could be an important adjuvant due to its action on the macrophage cells, which extends its compound action on related microbial growth control. These are promising results, showing the potential biopharmaceutical uses for xylitol in macrophage adhesion cells. 


\section{ACKNOWLEDGMENTS}

This work was supported by Fundação de Amparo à Pesquisa do Estado de Minas Gerais (FAPEMIG) (process number CBB APQ 11954.01/07). The authors want to acknowledge FAPEMIG and CNPq.

\section{REFERENCES}

Brandley, B.K., Schnaar, R.L. (1986), Cell-surface carbohydrates in cell recognition and response. $J$. Leukoc. Biol., 40, 97-111

Chen, Y., Duan, J., Qian, D., Guo, J., Song, B., Yang, M. (2010), Assessment and comparison of immunoregulatory activity of four hydrosoluble fractions of Angelica sinensis in vitro on the peritoneal macrophages in ICR mice. Int. Immunopharmacol., 10, 422-430

Ferreira, A.S., Souza, M.A., Barbosa, N.R., Silva, S.S. (2008), Leishmania amazonesis: Xylitol as inhibitor of macrophage infection and stimulator of macrophage nitric production. Exp. Parasitol., 119, 74-79

Foxwell, A.R., Kyd, J.M., Cripps, A.W. (2001), Programmed inflammatory processes induced by mucosal immunization. Vaccine, 19, 2522-2526

Geissmann, F., Manz, M. G., Jung, S., Sieweke, M. H., Merad, M., Ley K. (2010), Development of Monocytes, Macrophages, and Dendritic Cells. Science, 327, 656-661

Green, L.C., Wagner, D.A., Glogowki, J., Skipper, P.L., Wishnor, J.S., Tannenbaum, S.R. (1982). Analysis of nitrate, nitrite, and $[15 \mathrm{~N}]$ nitrate in biological fluids. Anal. Biochem., 126, 131-138

Han, S.J., Jeong, S.Y., Nam, Y.J., Yang, K.H., Lim, H.S., Chung, J. (2005), Xylitol inhibits inflammatory cytokine expression induced by lipopolysaccharide from Porphyromonas gingivalis. Clin. Diagn. Lab. Immunol., 12, 1285-1291

Hidemura, A., Sato, H., Fukatsu, K., Matsuda, T., Kitayama, J., Ikeda, S., Kang, W., Nagawa, H. (2003), Oral administration of Bifidobacterium longum culture condensate in a diet-restricted murine peritonitis model enhaces polymorphonuclear neutrophil recruitment into the local inflammatory site. Nutrition, 19, 270-274

Kadl, A., Leitinger, N. (2005), The role of endothelial cells in the resolution of acute inflammation. Antioxid. Redox Signal., 11-12, 1744-1754

Kontiokari, T., Uhari, M., Koskela, M. (1998), Antiadhesive effects of xylitol on otopathogenic bacteria. J. Antimicrob. Chemother., 41, 563-565.
Lasser, A. (1983), The mononuclear phagocytic system: a review. Hum. Pathol., 14, 108-126

Lloyd, D.H., Viac, J., Weling, D., Rème, C.A., Gatto, H. (2007), Role of sugars in surface microbe-host interactions and immune reaction modulation. Vet. Dermatol., 18, 197-204

'Lon' Jones, A.H. (2003), The next step in infectious disease: taming bacteria. Med. Hypotheses, 60, 171174

Masako, K., Hideyuki, I., Shigeyuki, O., Zenro, I. (2005), A novel method to control the balance of skin microflora. Part 1. Attack on biofilm of Staphylococcus aureus without antibiotics. J. Dermatol. Sci., 38, 197-205

Mosser, D. M. (2003), The many faces of macrophage activation. J. Leuk. Biol., 73, 209-212

Mosmann, T. (1983), Rapid colorimetric assay for cellular growth and survival: application to proliferation and cytotoxicity assays. J. Immunol. Methods, 65, 55-63

Naaber, P., Letho, E., Salminen, S., Mikelsaar, M. (1996), Inhibition of adhesion of Clostridium difficile to Caco-2 cells. FEMS Immunol. Med. Microbiol., 14, 205-209

Pepper, T., Olinger, P.M. (1988), Xylitol in sugar-free confections. Food Technology, 42, 98-106

Perretti, M., Wheller, S.K., Harrix, J.G., Flower, R.J. (1996), Modulation of ICAM-1 levels on U-937 cells as mouse macrophages by interleukin-1 $\beta$ and dexamethasone. Biochem Biophys Res Commun., 223, 112-117

Persson, U., Hammarström, L., Möller, E., Möller, G., Smith, C.I.E. (1978), The role of adherent cells in B and $\mathrm{T}$ lymphocyte activation. Immunol. Rev., 40, 78101

Sajjan, U., Moreira, J., Liu, M., Humar, A., Chaparro, C., Forstner, J., Keshavjee, S. (2004), A novel model to study bacterial adherence to the transplanted airway: inhibition of Burkholderia cepacia adherence to human airway by dextran and xylitol. J. Heart Lung Transplant., 23, 1382-1391

Steibnerg, L.M., Odusola, F., Mandel, I.D. (1992), Remineralizing potential, antiplaque and antigingivitis effects of xylitol and sorbitol sweetened chewing gum. Clin. Prev. Dent., 14, 31-34

Takahashi, K., Nakanishi, T., Yumoto, H., Adachi, T., Matsuo, T. (2005), CCL20 production is induced in human dental pulp upon stimulation by Streptococcus mutans and proinflammatory cytokines. Oral Microbiol. Immunol., 23, 320-327

Tiwari, R. L., Singh, V., Barthwal, M.K. (2008), Macrophages: an elusive yet emerging therapeutic target of atherosclerosis. Med. Res. Rev., 28, 483-544

Vernacchio, L., Vezina, R.M., Mitchell, A.A. (2007), Tolerability of oral solution in young children: implications for otitis media prophylaxis. Int. J. Pediatr. Otorhinolarylgol., 71, 89-94 
Zabner, J., Seiler, M.P., Launspach, J.L., Karp, P.H., Kearney, Look, D.C., Smith, J.J., Welsh, M.J. (2000), The osmolyte xylitol reduces the salt concentration of airway surface liquid and may enhance bacterial killing. Proc. Natl. Acad. Sci. USA, 97, 11614-11619
Zopf, D., Roth, S. (1996), Oligosaccharide antiinfective agents. Lancet, 347, 1071-1021

Received: August 19, 2010; Revised: January 20, 2011; Accepted: August 16, 2011. 